\title{
Positive effect on patient experience of video- information given prior to cardiovascular magnetic resonance imaging, a clinical trial.
}

Britt-Marie Ahlander, J an Engvall, Eva Maret and Elisabeth Ericsson

The self-archived postprint version of this journal article is available at Linköping University Institutional Repository (DiVA):

http:/ / urn.kb.se/ resolve?urn=urn:nbn:se:liu:diva- 143295

N.B.: When citing this work, cite the original publication.

Ahlander, B., Engvall, J ., Maret, E., Ericsson, E., (2017), Positive effect on patient experience of videoinformation given prior to cardiovascular magnetic resonance imaging, a clinical trial., J ournal of Clinical Nursing, , StartPage-EndPage. https:// doi.org/ 10.1111/jocn.14172

Original publication available at:

https:/ / doi.org/ 10.1111/jocn. 14172

Copyright: Wiley (12 months)

http:// eu.wiley.com/WileyCDA/ 


\section{Positive effect on patient experience of video- information given prior to cardiovascular magnetic resonance imaging, a randomized clinical trial}

Britt-Marie AHLANDER: RN, Radiographer (MRI), PhD, Department of Radiology, Ryhov County Hospital, SE-55185 Jönköping, Sweden.

Jan ENGVALL: MD, PhD, Professor, Department of Clinical Physiology, Linköping University, SE-581 83 Linköping, Sweden. Center of Medical Image Science and Visualization, Linköping University, SE-581 83 Linköping, Sweden.

Eva MARET: MD, PhD, Department of Clinical Physiology, Karolinska Institutet, and Karolinska University Hospital, SE-14186 Stockholm, Sweden.

Elisabeth ERICSSON: RN, PhD, Associate Professor, Faculty of Medicine and Health, School of Health Science, Örebro University, SE-701 82 Örebro, Sweden.

*Corresponding author address:

britt-marie.ahlander@oru.se britt-marie.ahlander@ju.se Tel.: (+46)707652189 Department of Radiology Ryhov County Hospital SE-55185 Jönköping Sweden

The authors gratefully thank the staff in the MRI-units and the unit of Clinical Physiology at the participating hospitals for valuable assistance.

The authors have no conflicts of interest.

This study was supported by grants from Futurum, County Council of Jönköping and by the Division of Medical Diagnostics, Region Jönköping county Sweden. 


\begin{abstract}
AIMS: To evaluate the effect of video information given before cardiovascular magnetic resonance imaging on patient anxiety and to compare patient experiences of cardiovascular magnetic resonance imaging versus myocardial perfusion scintigraphy.

To evaluate if additional information has an impact on motion artefacts.
\end{abstract}

BACKGROUND: Cardiovascular magnetic resonance imaging and myocardial perfusion scintigraphy are technically advanced methods for the evaluation of heart diseases. Although cardiovascular magnetic resonance imaging is considered to be painless, patients may experience anxiety due to the closed environment of the procedure.

DESIGN: A prospective randomized intervention study.

METHODS: The sample $(n=148)$ consisted of 97 patients referred for cardiovascular magnetic resonance imaging, randomized to receive either video information in addition to standard textinformation (CMR-video/n=49) or standard text-information alone (CMR-standard/n=48). A third group undergoing myocardial perfusion scintigraphy $(n=51)$ was compared with the cardiovascular magnetic resonance imaging-standard group. Anxiety was evaluated before, immediately after the procedure and one week later. Five questionnaires were used: Cardiac Anxiety Questionnaire, StateTrait-Anxiety Inventory, Hospital-Anxiety and Depression-scale, MRI-Fear-Survey-Schedule and the MRI-Anxiety-Questionnaire. Motion artefacts were evaluated by three observers, blinded to the information given. Data were collected between April 2015 and April 2016.

RESULT: The CMR-video group scored lower (better) than the cardiovascular magnetic resonance imaging-standard group in the factor Relaxation $(p=0.039)$ but no difference was found in the factor Anxiety. Anxiety levels were lower during scintigraphic examinations compared to the CMR-standard group ( $p<0.001)$. No difference was found regarding motion artefacts between $C M R$-video and CMRstandard.

CONCLUSION: Patient ability to relax during cardiovascular magnetic resonance imaging increased by adding video information prior the exam, which is important in relation to perceived quality in nursing. No effect was seen on the presence of motion artefact.

RELEVANCE TO CLINICAL PRACTICE: Video information prior to examinations can be an easy and time effective method to help patients cooperate in imaging procedures. 


\section{Summary box}

What does this paper contribute to the wider global clinical community?

- Video information prior to examinations can be an easy and time effective method to help patients cooperate in imaging procedures and can be distributed as a web link or be shown as video clips in the waiting room.

- Video information could be especially suited to people that cannot read and to patients with cognitive deficits. Video information can be translated to any language and contribute to better healthcare in multiethnic societies.

- For patients, myocardial perfusion scintigraphy was easier to tolerate than cardiovascular magnetic resonance imaging.

\section{Keywords}

nursing, video information, patient experience, patient information, cardiovascular magnetic resonance imaging, myocardial perfusion scintigraphy. 


\section{INTRODUCTION}

Optimal treatment for coronary artery disease is facilitated by early diagnosis (Fox et al. 2006).

Patient history and clinical signs initiate a workup (Fox et al. 2006, Roffi et al. 2016) which frequently takes the patient to an invasive coronary angiography (ICA), even if we know that $40 \%$ or more of ICA will not result in a revascularization procedure (SWEDEHEART registry 2015). Other imaging methods are used to support diagnostics as well as for screening those with an intermediate cardiovascular risk. In this study, we have focused on cardiovascular magnetic resonance imaging (CMR) and myocardial perfusion single photon emission computed tomography (MPS). Both methods are well established and have a spectrum of advantages as well as disadvantages (Marcassa et al. 2008, Kim et al. 2009, Charoenpanichkit and Hundley 2010, Mielniczuk et al. 2017). One particular advantage for $C M R$ is the freedom from radiation exposure to the patient.

Magnetic resonance imaging (MRI), the technique used performing the examination CMR and single photon emission computed tomography (SPECT), the technique used when performing MPS, are both advanced technologies which require the full attention of the radiographers. This can effectively alienate them from the experience of the patient (Adler 1990). During MRI examinations, patients are positioned in the center of the scanner tunnel which has the full length of an adult. The scanning radiographers direct the study from an adjacent room (McRobbie et al. 2007) which may create a sense of distance between the patient and the staff. Furthermore, the narrow tunnel may elicit claustrophobic feelings compounded by the high-pitched noise during the examination (Carlsson \& Carlsson 2013). SPECT requires the patient to rest supine with raised arms during scanning, but the scanner design is open and the technician easily available within a short distance. MRI examinations are known to provoke anxiety in some patients (Murphy 2001, Harris et al. 2004, Tornqvist et al. 2006b, Katznelson et al. 2008, Tazegul et al. 2015) but very little is known about patient experience during SPECT (Munn and Jordan 2011, Nightingale et al. 2012). Not only the examination itself may provoke anxiety, but the patient anxiousness regarding the result from the examination may provoke anxiety (Easton et al. 2016) which may negatively affect their experience. Many studies have 
compared the diagnostic value of CMR and MPS (Schwitter et al. 2012, Schwitter et al. 2013, Shaw et al. 2014, Ahmad et al. 2015) but no one has compared these methods from the aspect of patient comfort, which is important to the quality of health care.

\section{BACKGROUND}

Patients undergoing investigations are in a situation that can be characterized as a state of helplessness due to a perceived inability to control result and outcome in a vulnerable situation. The future can be perceived as ominous as well. These feelings are identical to those defined by Barlow as anxiety (Barlow 2000). Being a patient is to be in a situation that is unknown, for many people different from anything experienced earlier. Often patients have little to rely upon helping them to understand what is going on (McHugh et al. 1982).

Procedure-related information gives the patients a structure to interpret their experience. It has been shown that information attracting our senses help patients cope with instructions. Sensory information incorporates sight, hearing, touch, taste and smell. Further, video is a medium that is familiar to most people and has demonstrated positive results when used prior to surgical procedures (Lin et al. 2015). When information is provided prior to an MRI scan, anxiety may be reduced (Luck et al. 1999, Tazegul et al. 2015). Patients who understand comply with instructions (Llewelyn and Ley 1995) and express a higher degree of satisfaction (Selim 2001) than those unfamiliar with the procedure. However, the way information is given and received is crucial. Information content and language should be easy to understand, without medical terminology (Rajasundaram et al. 2006).

Tornqvist et al. have shown that extensive written information is not sufficient to decrease patient anxiety during MRI examinations (Tornqvist et al. 2006a). Video information attracts both eye sight and hearing. Further, video is also a medium that is familiar to many people. As such it has been used before surgical operations with positive results (Sorlie et al. 2007,Lin et al. 2015). Yet, we don't know what effect video information in addition to standard written information could have on patient 
anxiety during CMR. Tornqvist et al also showed that additional written information decreased motion artefacts, even if it did not decrease patient anxiety (Tornqvist et al. 2006a).

MRI and SPECT are both used for cardiac imaging and some patients are investigated with both. Patient experience when undergoing SPECT has received little attention (Munn and Jordan 2011, Nightingale et al. 2012). In order to treat the patients with respect and to understand their feelings and behaviour, health care professionals have to be aware of the patients own experience.

\begin{abstract}
Aims
The primary aim was to evaluate the effect of video information given before CMR on patient anxiety and to compare patient experiences of CMR versus MPS. Secondarily, to evaluate if additional information has an impact on motion artefacts.
\end{abstract}

\title{
Hypothesis
}

We hypothesized that additional video information about the CMR procedure would reduce anxiety and motion artefact and that having a CMR scan would be more anxiety-ridden than undergoing MPS.

\section{METHODS}

\section{Study design}

The study was designed as a prospective randomized intervention study.

\section{Data collection}

\section{Participants}

Outpatients from the waiting list referred for a cardiac study using one of the two modalities, MRI or SPECT, were consecutively asked to participate. Three groups of patients were defined. Two groups underwent $\mathrm{CMR}$, one which was given video information in addition to standard written information (CMR-video) and the second group received standard written information only (CMR-standard). The third group underwent MPS at rest and received standard written information relevant for the procedure. 
When the patients arrived at the MRI-unit they were randomized by a radiographer, with the help of even or odd numbers in a 1:1 ratio, to one of the two CMR-groups: the patients with even numbers were assigned to the CMR-video group and the patients with odd number to the CMR-standard group.

In order to minimize the risk for bias the randomization was performed before the radiographer met the patient, by using even and odd numbers. The patient experience of being examined in either modality was evaluated using a comparative design. A flow chart for all three groups is presented in Figure 1. The sample was recruited between April 2015 and April 2016. Inclusion criteria were age 18 years or above and ability to read, understand, and speak the Swedish language. Exclusion criteria were contraindications for the examinations. All CMR studies were performed with contrast injection. All examinations were performed at rest, without use of pharmacologic or physical stress.

\section{Standard patient information regarding CMR and MPS}

The letter scheduling the appointment included appropriate information about the examination procedure for CMR or MPS. The text for CMR explained positioning in the MRI-scanner, the requirement of being immobile for parts of the study, the noise to be expected during the examination, and that an intravenous injection with contrast media was needed. The text for the MPS group recommended fasting before the procedure and explained that the injection of an isotope would be needed. All groups received oral information throughout the examinations.

\section{Specific information for CMR-video}

In order to evaluate the possible advantage from extended information, a five-minute long video was produced specifically for this study. To identify information needs, the available literature was searched from PubMed and Cinahl. The search identified the following issues that needed better description: the enclosed, narrow scanning tunnel, the noise created by the changing magnetic field and the duration of the scan which is much longer than other radiological examinations (Carlsson \& Carlsson 2013). Providing patient with information about the examination procedure helps coping. Information appealing to our senses makes it easier for the patient to interpret their experience 
(McHugh et al. 1982). To ensure the proper content of the video, patients were asked about their needs and the final video was also evaluated by a small ad hoc group of patients before the study started. Patients in the intervention group were given the recording on a laptop before the examination, with an actor playing the role of the patient. The video shows the entire procedure, starting with the radiographer interviewing the patient in order to ascertain that contraindications are not present. The video then goes on to show patient preparation with the application of ECG leads, a percutaneous vein catheter, a surface coil on the chest for imaging, ear muffs and an alarm. The need for immobilization and breath holding is repeated. The video ends with the patient leaving the CMR suite. After watching the video the patients had the possibility to ask the radiographer about the examination procedure before the examination started. During the study period patients were given positive feedback.

\section{Procedure and outcomes}

The primary outcome was patient anxiety and feelings measured immediately before and after the examinations. To evaluate the intensity of the memory, the patient compliance of the scanning procedure and the anxiety it provoked, a one-week follow-up was performed.

Secondary outcomes were differences in the patient experience of MRI and MPS. The two modalities have different requirements in terms of patient participation. To ensure that the testing situation was analogous and to minimize bias, both groups received standard written information.

A tertiary outcome was to evaluate potential differences in image quality between the CMR-video and the CMR-standard groups. Image quality was evaluated in terms of motion artefacts, since they are heavily influenced by patient cooperation. Three observers blinded towards the information given to the patients rated image quality on cine images of the three long axis and all short axis slices. Motion artefact was present if blurring (arrhythmia excluded) was seen in at least two slices. In a secondary step, a patient was considered to have motion artefact if determined by at least two observers. 
All participants answered questions regarding age and gender, medication for hypertension, previous percutaneous coronary intervention (PCI), coronary artery bypass graft (CABG) surgery, and treatment for psychological disorders. They also responded to questionnaires (Table 1) evaluating cardiac anxiety, anxiety in life, and anxiety about situations related to MRI. After filling out the questionnaires, the intervention group (CMR-video) watched the short video followed by the CMR procedure. Verbal information about the progress of the examination was continuously given to all patients. Participant anxiety and feelings were measured before, immediately after the examination as well as one week later (Table 1).

\section{Assessment Instruments}

Cardiac Anxiety Questionnaire (CAQ) (Eifert et al. 2000), consists of 18 statements divided into three subscales assessing heart focused anxiety. The factors are fear (eight statements), avoidance, and attention (five statements each). The statements are rated on a five-point scale, ranging from 0 (never) to 4 (always), where a higher score indicates more intense heart focused anxiety. The score ranges from 0 to 72 . Cronbach alpha in the present study was 0.87 for the scale and $0.78,0.90,0.60$ for the factors, respectively.

Spielberg State and Trait Anxiety Index -State (STAI) (Spielberger 1970, Ferreira and Murray 1983) consists of two separate scales with 20 items each, measuring state (situational) and trait (baseline) anxiety. In the present study, only the state anxiety scale was used (STAI-S), which measures the anxiety patients experience at a particular moment. Patients rate their feelings on a four-point scale ranging from "not at all" to "very much", with a possible score range between 20 and 80 . High scores imply a higher level of anxiety. Cronbach alpha in the present study was 0.93 .

Hospital Anxiety and Depression Scale (HAD) (Zigmond and Snaith 1983, Bjelland et al. 2002) measures general anxiety and depression in patients. It consists of two subscales with seven questions about anxiety and seven questions about depression. Both are rated on a four-point scale, where a higher score indicates a higher level of anxiety and depression. The possible score ranges 
between 0 and 21 for each scale. In the present study, Cronbach alpha was 0.82 for depression and 0.86 for anxiety.

Magnetic Resonance Imaging Fear Survey Schedule (MRI-FSS) consists of nine statements from the Fear Survey Schedule (Wolpe and Lang 1964), defined by Lukins et al (Lukins et al. 1997). These nine statements deal with fear in situations related to MRI examinations and were developed to predict fear during such examinations (Harris et al. 2004). Patients rate the statements on a seven-point scale ranging from "no fear at all" to "terrified". Higher scores predict higher levels of anxiety during the examination. The score ranges between 9 and 63. Cronbach alpha in the present study was 0.85 . Magnetic Resonance Imaging - Anxiety Questionnaire (MRI-AQ) measures patient anxiety during MRI examinations (Ahlander et al. 2016). It consists of 15 statements divided into two subscales (anxiety and relaxation) rated on a four-point scale. The score ranges between 15 and 60 . Higher scores indicate higher levels of anxiety. Cronbach alpha in the present study was 0.87 for the total scale, 0.85 for the factor anxiety and 0.89 for the factor relaxation.

The patients graded the information they received from $1=$ very good, to $10=$ very bad. The patients and the staff independently graded patient experience and worry on a ten-point scale, from 1=very good to 10 very bad.

\section{Ethical considerations}

The investigation conformed to the principles outlined in the Declaration of Helsinki (World Medical Association 2001) and the principles of Good Clinical Practice (Group 1996). Approval was obtained from the Regional Ethical Review Board and all participating patients gave written informed consent after a full explanation of the planned procedure. The patients were informed that study participation was voluntary and that they could withdraw from participation whenever they wished without negative consequences. 


\section{Data analysis}

Descriptive statistics were used to present participant characteristics. Parametric data was expressed as mean \pm standard deviation (SD). Nonparametric data was expressed as median and inter-quartile range (IQR). Student's t-test was used for test of significance of parametric data.

For comparison of data on a nominal level, Fisher's exact two-tailed test was used. For data on an ordinal scale level, non-Gaussian distributed according to the Kolmogorov-Smirnov test, median and quartiles were used to describe data. The Wilcoxon signed-rank test was used for comparison of preexamination and post-examination data. The Mann-Whitney U-test was used for comparison between study groups. Spearman's rank-correlation coefficient $\left(r_{s}\right)$ was used for the correlation between questions.

Analysis of covariance was used to adjust for age in the comparison of anxiety between the two groups CMR-standard and MPS, and for gender between CMR-standard and CMR-video. Significance was evaluated with the Tukey-test.

The calculation of sample size was based on the prevalence of anxiety in patients undergoing MRI examinations in previous research (Selim 2001). Based on an expected effect size of $40 \%$, an alpha set at 0.05 and a power of 0.80 , a sample size of 50 participants in each study group was necessary. Data was analyzed using STATISTICA version 10 (StatSoft, Inc., Tulsa, USA).

A two-tailed $p$-value $\leq 0.05$ was regarded as statistically significant.

\section{RESULTS}

\section{Participants}

Two hundred and fourteen patients were invited and 150 accepted to participate. Two patients prematurely interrupted the examination (one in each CMR group) giving a response rate of $69 \%$. One hundred and five patients answered the questionnaires a third time, after one week (Fig. 1). No age difference was found in the CMR-groups between those who participated in the study, $49.2 \pm 14.9$ years, and those who declined, $46.0 \pm 17.5$ years, $(p=0.294)$. For MPS, the age of the participants was, $64.5 \pm 8.9$ years, and the non-participants, $68.2 \pm 11.2$ years, $(p=0.113)$. The ratio of males to females 
was similar among participants and non-participants. All examinations were performed by experienced staff, with 5-15 years work experience. Information on patient baseline characteristics is given in table 2.

No baseline difference was found between the CMR-groups regarding anxiety (STAI-S, HAD-A), depression (HAD-D), heart focused anxiety (CAQ total scale and factors), and anxiety in situations related to MRI examinations (MRI-FSS). Significant baseline differences were found between CMRstandard and MPS for CAQ attention ( $p=0.032)$, HAD-A $(p=0.010)$, and MRI-FSS $(p=0.020)$, where the CMR-standard group scored a higher level of anxiety before the examination (Table 3).

\section{Results immediately after the procedure}

The intervention group, CMR-video, scored significantly lower than the control group in the factor Relaxation ( $p=0.039$ ) (Table 3). When adjusted for gender, the difference between the groups still remained (Table 4). There was no significant difference in MRI-AQ, total score and the factor Anxiety between the CMR-video and CMR-standard groups.

There was no difference (MRI-AQ) between patients who had undergone previous MRI examinations or the patients who took the examination for the first time $(p=0.956)$.

Compared with MRI-AQ-responses in the MPS group, the CMR-standard group scored significantly higher both in total score $(p<0.001)$ and in the factors Anxiety $(p<0.001)$ and Relaxation $(p=0.029)$ (Table 3). When adjusted for age, the difference between the groups still remained (Table 4).

No difference was found in the rating of experience and worry between the two CMR groups. No difference was found between patient and staff ratings of patient experience and worry.

The correlation between the MRI-AQ total scale, the factor Anxiety, the factor Relaxation and the other instruments varied between $r_{s}=0.207$ and 0.684 . Low or no correlation was found for CAQ avoidance and HAD-D (Table 5). 
Situational anxiety (STAI-S) decreased from before the examination to immediately after the examination in all three study groups CMR-video $(p<0.001), C M R$-standard $(p=0.001)$ and MPS $(p=0.001)$.

\section{Sub-groups analyses of the two CMR-groups}

In a sub-group analysis of results in relation to patient age ( $\leq 49$ years and $>49$ years which was the median age), young participants scored significantly higher than older participants in MRI-AQ responses for the factor Anxiety $(p=0.034)$ and STAI-S $(p=0.004)$.

Women scored significantly higher than men in MRI-AQ total scale $(p=0.028)$ and in the factor Anxiety $(p=0.015)$. In the factor Relaxation, no difference was found between the genders (Table 6). In the remaining instruments, women scored higher on the CAQ subscales Fear $(p=0.013)$ and Attention ( $p=0.021)$, as well as on the subscale of HAD-A $(p=0.001)$, the STAI-S $(p=0.001)$, and on MRI-FSS $(p=<0.001)$.

\section{Results one week after the examinations}

In the three study groups (CMR-S, CMR-V, MPS), the results in the total scale MRI-AQ, the factor Anxiety, and the factor Relaxation showed no significant changes immediately before and one week after the examination.

Heart focused anxiety determined by the CAQ score, was not different before and one week after the examination [CMR-standard $(p=0.838)$, MPS $(p=0.388)]$. Statements dealing with fear in situations related to MRI examinations (MRI-FSS) showed no difference after one week, compared to before the examination

\section{Comparison of image quality}

The presence of motion artefact, as an indirect expression of the degree of patient anxiety and cooperation, was similar in the CMR-groups, both intervention ( $20 \%)$ and control ( $20 \%, p=1.000)$. The reproducibility between the observers showed $71-74 \%$ agreement. 


\section{DISCUSSION}

Video information describing the examination procedure prior to a CMR-examination increased patient relaxation. Even if not formally evaluated, the MRI technicians found video information to facilitate patient comfort during scanning. Patient comfort is an important aspect of quality in nursing care.

This difference was present even when adjusted for gender. No difference was found for the factor Anxiety, which expresses a state of helplessness, a sense of uncontrollability focusing on a future threat or danger (Barlow 2000). Larger study groups with larger diversity could possibly have rendered a different result for "Anxiety".

Patients with cardiac disease might experience a general sense of anxiety in connection with their disease (Easton et al. 2016), which could negatively affect their participation in the imaging procedures. However, this study showed a very low or absent correlation between heart focused anxiety and patient anxiety during the examination.

Measured with MRI-AQ women scored significantly higher levels of anxiety than men, which is in line with other studies (Luck et al. 1999, Tornqvist et al. 2006a). This indicates that they experienced the same positive effect of the video information on relaxation despite different levels of anxiety.

In the analysis, MPS was found to be better tolerated than CMR when the two groups with standard written information were compared. This difference is still present after adjusting for age. The scanning position in the gamma camera is relatively open compared to the MRI scanner, and the staff can be easily available to assist the patients during the examination. The diagnostic power of MPS and CMR has often been compared when investigating perfusion (Schwitter et al. 2012, Schwitter et al. 2013, Shaw et al. 2014, Ahmad et al. 2015) but the influence on patient experience is largely unknown. MPS patients expressed lower anxiety before the examination than the CMR patients, possibly due to having performed image acquisition a few days earlier in connection with a cardiac 
stress test and they were also older. Since the two investigations provide different information, the referring physician cannot select on patient preferences only.

Timing information could be important. In this study information was given immediately before the examination. However, other studies have suggested that this is not the best time to inform (Luck et al. 1999). Patients may be too nervous and distracted by events associated with the examination, and may have difficulties concentrating on the information provided. We therefore suggest that video information could be provided in the appointment letter as a link to a web page. Video-based information can then be made available in different languages to fit multicultural societies as well as being repeated if needed. McHugh et al stated that information shall be sensory, it is what we see, hear, touch, taste and smell (McHugh et al. 1982). Since video information is both visual and verbal it could possibly better satisfy patient needs (Munn and Jordan 2011) and be suitable for a larger group of patients.

Anxiety decreased over time in the three study groups, measured with STAI-S. Depression was at the same level before and one week after the examination, indicating that depression probably is not affected by an imaging procedure. Temporal changes in MRI-AQ total scale and the factors Anxiety and Relaxation were not found. This indicates that the patients could easily recall their feelings from the examination, which indicates that these memories were strong. MRI-FSS, which measures fear in situations related to MRI, such as fear of loud noise or of enclosed places, showed similar result before and one week after the examination. Even if other studies have reported that this kind of fear can increase after an examination (Lukins et al. 1997), this was not the case in the present study.

The CMR-standard group and the CMR-video group expressed similar satisfaction with the information given. Hypothetically, the standard text-based information in connection with information given by the staff satisfied all needs, or the patients who received text-based information could not imagine what video could provide. Patients and staff rated anxiety and worry of the patients very similarly. All staff performing examinations with CMR-and MPS was technically 
well trained and had a caring eye. The impact of video information could possibly have been larger if the staff had been less experienced. Still, a significant difference could be found between those who received video information before their cardiac MRI scan and those who did not. However, information can never replace the presence of experienced staff knowing the kind of support the patients may need. Images provided by video could enhance pre-study information, but Murphy et al. found that the interaction between patients and staff is very important (Murphy 2001).

Extent of motion artefacts was not influenced by the video information. Even if motion artefacts depend on patient cooperation, other factors are also at play. Patients with a heart condition may have difficulties in breath holding, independent of information. The radiographer performing the examination also has a very important role encouraging the patients to do their very best and continue the exam until high quality images have been obtained. In this study all radiographers were experienced, which could have compensated for difficulties in the text-based group. The total number of artefacts is influenced not only by the well-being of the patients but also by technical specifications such as gradient strength of the scanner.

\section{LIMITATIONS}

To avoid bias, the radiographer randomized the patient to one of two groups with the help of even and odd numbers, before seeing the patient in the scanner suite.

The sample size was calculated based on the results from a study where additional oral information was given before the examination (Selim 2001). If the study groups had been larger in the present study and the differences between participants greater, the result could have been impacted. Future studies should take a larger sample size into consideration.

In this study, the staff was well trained guiding patients through the examinations which could have partly off-set problems related to anxiety. In situations with less experienced staff, the result could have been different. 
Staff and patients evaluated patient scanning experience using very simple scales in order to facilitate the procedure and ensure participation.

Participants were required to speak and understand the Swedish language. Video information in the native language of any potential patient could have expanded the benefit to this category of patients who frequently are difficult to coach in the scanner. This aspect was not evaluated in the present study but video information in native languages could possibly better prepare patients for the examination. Further research into this area is needed.

An optimal evaluation of image quality would ideally be based on images obtained with identical scanners. Our study design allowed us to investigate the influence of information regardless of scanner performance.

\section{CONCLUSION}

Video information prior to a CMR-examination increased patient relaxation and improved patient comfort, which is important when evaluating the quality of healthcare. Patients who underwent CMR had higher levels of anxiety during the examinations than those who underwent MPS, even when adjusted for age, which demonstrates that CMR is a demanding method on the part of the patient.

\section{RELEVANCE TO CLINICAL PRACTICE}

Prior to radiological procedures, patients need relevant information helping them to cooperate and to relax during the examination. Video information prior to examinations is of great value to all patients, not only when undergoing CMR. Video can be provided either as a link to a webpage or as a video clip available in the waiting room.

\section{Author contributions}

All authors have agreed on the final version and meet the following criteria recommended by the ICMJE (http://www.icmje): 
1) Substantial contributions to conception and design of, or acquisition of data or analysis and interpretation of data,

2) Drafting the article or revising it critically for important intellectual content and

3) Final approval of the version to be published.

The authors have no conflict of interest. 


\section{REFERENCES}

Adler, A.M. (1990) High technology: miracle or malady for patient care. Radiologic Technology, 61(6), 478-81.

Ahlander, B.M., Arestedt, K., Engvall, J., Maret, E. \& Ericsson, E. (2016) Development and validation of a questionnaire evaluating patient anxiety during Magnetic Resonance Imaging: the Magnetic Resonance Imaging-Anxiety Questionnaire (MRI-AQ). Journal of Advanced Nursing. 72(6):1368-80. doi: 10.1111/sjop.12282.

Ahmad, I.G., Abdulla, R.K., Klem, I., Margulis, R., Ivanov, A., Mohamed, A. ,... Borges-Neto Heitner, J.F. (2015) Comparison of stress cardiovascular magnetic resonance imaging (CMR) with stress nuclear perfusion for the diagnosis of coronary artery disease. Journal of Nuclear Cardiology, 23(2):287-97. doi: 10.1007/s12350-015-0242-0.

Barlow, D.H. (2000) Unraveling the mysteries of anxiety and its disorders from the perspective of emotion theory. Ameriacan Psychoogical, 55(11):1247-63. doi.org/10.1037/0003066X.55.11.1247.

Bjelland, I., Dahl, A.A., Haug, T.T., \& Neckelmann, D. (2002) The validity of the Hospital Anxiety and Depression Scale: an updated literature review. Journal of psychosomatic research, 52(2), 6977. doi.org/10.1016/S0022-3999(01)00296-3.

Carlsson, S., \& Carlsson, E. (2013) 'The situation and the uncertainty about the coming result scared me but interaction with the radiographers helped me through': a qualitative study on patients' experiences of magnetic resonance imaging examinations. J Clin Nurs 22, 32253234. 10.1111/jocn.12416.

Charoenpanichkit, C., \& Hundley, W.G. (2010) The 20 year evolution of dobutamine stress cardiovascular magnetic resonance. Journal of Cardiovascular Magnetic Resonance, 12, 59. doi: 10.1186/1532-429X-12-59

Easton K., Coventry P., Lovell K., Carter, LA., \& Deaton, C. (2016) Prevalence and Measurement of Anxiety in Samples of Patients With Heart Failure: Meta-analysis. J Cardiovasc Nurs 31, 367379. doi: $10.1097 / \mathrm{JCN} .0000000000000265$.

Eifert, G.H., Thompson, R.N., Zvolensky, M.J., Edwards, K., Frazer, N.L., Haddad, J.W. \& Davig, J. (2000) The Cardiac Anxiety Questionnaire: development and preliminary validity. Behaviour research and therapy, 38(10), 1039-1053. doi.org/10.1016/S0005-7967(99)00132-1.

Ferreira, R., \& Murray, J. (1983) Spielberger's State-Trait Anxiety Inventory: Measuring anxiety with and without an audience during performance on a stabilometer. Perceptual and Motor Skills 57(1), 15-8. doi: 10.2466/pms.1983.57.1.15.

Fox K, Garcia MA, Ardissino D, Buszman P, Camici PG, Crea F, ... Zamorano JL (2006) Guidelines on the management of stable angina pectoris: executive summary: The Task Force on the Management of Stable Angina Pectoris of the European Society of Cardiology. Eur Heart J 27, 1341-1381. DOI:10.1093/eurheartj/ehl001.

Group I. C. o. H. W. (1996) ICH Harmonised Tripartite Guideline: Guideline for Good Clinical Practice E6 (R1). Paper presented at the International Conference on Harmonisation of Technical Requirements for Registration of Pharmaceuticals for Human Use.

Harris, L.M., Cumming, S.R., \& Menzies, R.G. (2004) Predicting anxiety in magnetic resonance imaging scans. International Journal of Behavioral Medicine, 11(1), 1-7. doi: 10.1207/s15327558ijbm1101_1.

Katznelson, R., Djaiani, G.N., Minkovich, L., Fedorko, L., Carroll, J., Borger, M.A., Cusimano, R.J., \& Karski, J. (2008) Prevalence of claustrophobia and magnetic resonance imaging after coronary artery bypass graft surgery. Neuropsychiatric Disease and Treatment, 4(2), 487-93.

Kim, H.W., Farzaneh-Far, A., \& Kim, R.J. (2009) Cardiovascular magnetic resonance in patients with myocardial infarction: current and emerging applications. Journal of the American College of Cardiology, 55(1), 1-16. doi:10.1016/j.jacc.2009.06.059. 
Lin, S.Y., Huang, H.A., Lin, S.C., Huang, Y.T., Wang, K.Y., \& Shi, H.Y. (2015) The effect of an anaesthetic patient information video on perioperative anxiety: A prospective randomised study.

European Journal of Anaesthesiology. 60(11):843-847 doi: 10.1097/EJA.0000000000000307

Llewelyn, S.. \& Ley, P. (1995) Improving patients' understanding, recall, satisfaction and compliance. In Health psychology: Process and applications(Broome, A. and Llewelyn, S. eds.) Chapman \& hall, London, UK, pp. 75-98.

Luck, A., Pearson, S., Maddern, G., \& Hewett, P. (1999) Effects of video information on precolonoscopy anxiety and knowledge: a randomised trial. Lancet, 354(9195), 2032-5. doi.org/10.1016/S0140-6736(98)10495-6.

Lukins, R., Davan, I.G.P., \& Drummond, P.D. (1997) A cognitive behavioural approach to preventing anxiety during magnetic resonance imaging. Journal of behavior therapy and experimental psychiatry, 28(2), 97-104. doi:10.1016/S0005-7916(97)00006-2.

Marcassa, C., Bax, J.J., Bengel, F., Hesse, B., Petersen, C.L., Reyes, ... Nucl, E.A. (2008) Cardiovasc Clinical value, cost-effectiveness, and safety of myocardial perfusion scintigraphy: a position statement. European Heart Journal, 29(4), 557-563. doi: http://dx.doi.org/10.1093/eurheartj/ehm607

McRobbie. DW., Moore, EA., Graves, MJ,. \& Prince, M.R. (2007) MRI From Picture to Proton, second edn. Cambridge University Press, Cambridge.

McHugh, N.G., Christman, N.J., \& Johnson, J.E. (1982) Preparatory information: what helps and why. American Journal of Nursing, 82(5), 780-2.

Mielniczuk, LM., Toth, GG., Xie, JX., De Bruyne, B., Shaw, L., \& Beanlands, RS. (2017) Can Functional Testing for Ischemia and Viability Guide Revascularization? JACC Cardiovasc Imaging 10, 354 364. doi: 10.1016/j.jcmg.2016.12.011.

Munn, Z., \& Jordan, Z. (2011) The patient experience of high technology medical imaging: a systematic review of the qualitative evidence. Radiography, 17(4), 323-331. doi.org/10.1016/j.radi.2011.06.004.

Murphy, F. (2001) Understanding the humanistic interaction with medical imaging technology. Radiography 7, 193-201. doi.org/10.1053/radi.2001.0328.

Nightingale, J.M., Murphy, F.J., \& Blakeley, C. (2012) 'I thought it was just an x-ray': a qualitative investigation of patient experiences in cardiac SPECT-CT imaging. Nuclear Medicine Communication, 33(3), 246-54. doi: 10.1097/MNM.0b013e32834f90c6.

Rajasundaram, R., Phillips, S., \& Clay, NR. (2006) Information leaflet used in out-patient clinics: a survey of attitude and understanding of the user. Int J Health Care Qual Assur Inc Leadersh Health Serv 19, 575-579.

Roffi, M., Patrono, C., Collet, JP., Muelle, r C., Valgimigli, M., Andreotti, F., ... Luis Zamorano, J. (2016) 2015 ESC Guidelines for the management of acute coronary syndromes in patients presenting without persistent ST-segment elevation: Task Force for the Management of Acute Coronary Syndromes in Patients Presenting without Persistent ST-Segment Elevation of the European Society of Cardiology (ESC). Eur Heart J 37, 267-315. doi: 10.1093/eurheartj/ehv320.

Schwitter, J., Wacker, C.M., Wilke, N., Al-Saadi, N., Sauer, E., Huettle, K., ... Simor, T. (2012) Superior diagnostic performance of perfusion-cardiovascular magnetic resonance versus SPECT to detect coronary artery disease: The secondary endpoints of the multicenter multivendor MRIMPACT II (Magnetic Resonance Imaging for Myocardial Perfusion Assessment in Coronary Artery Disease Trial). Journal of Cardiovascular Magnetic Resonance, 14, 61. doi: 10.1186/1532-429X-14-61.

Schwitter, J., Wacker, C.M., Wilke, N., Al-Saadi, N., Sauer, E., Huettle, K., ... Simor, T. (2013) MRIMPACT II: Magnetic Resonance Imaging for Myocardial Perfusion Assessment in Coronary artery disease Trial: perfusion-cardiac magnetic resonance vs. single-photon emission computed tomography for the detection of coronary artery disease: a comparative multicentre, multivendor trial. European Heart Journal, 34(10), 775-81. doi: doi.org/10.1093/eurheartj/ehs022. 
Shaw, L., Berman, DS., Picard, MH., Friedrich, MG., Kwong, RY., Stone, GW., ... Douglas, PS. (2014) Comparative definitions for moderate-severe ischemia in stress nuclear, echocardiography, and magnetic resonance imaging. JACC Cardiovasc Imaging 7, 593-604. doi: 10.1016/j.jcmg

Selim, M.A. (2001) Effect of pre-instruction on anxiety levels of patients undergoing magnetic resonance imaging examination. Eastern Mediterranean Health Journal, 7(3), 519-25.

Sorlie, T., Busund, R., Sexton, J., Sexton, H., \& Sorlie, D. (2007) Video information combined with individualized information sessions: Effects upon emotional well-being following coronary artery bypass surgery-A randomized trial. Patient Education and Counseling, 65(2), 180-8. doi: 10.1016/j.pec.2006.07.006.

Spielberger, C.D., Goursch, R.L., Lushene, R.E. (1970) Manual for the State-Trait Anxiety Inventory. Consulting Psychologist Press.

SWEDEHEART (2015) SWEDEHEART Annual report 2015. Vol. 2016 (Tillberg, M. ed. Jernberg, Tomas) available at: http://www.ucr.uu.se/swedeheart/index.php/dokument-sh/arsrapporter (accessed 15 July 2016).

Tazegul, G., Etcioglu, E., Yildiz, F., Yildiz, R., \& Tuney, D. (2015) Can MRI related patient anxiety be prevented? Magnetic Resonance Imaging, 33(1), 180-183. doi.org/10.1016/j.mri.2014.08.024.

Tornqvist, E., Mansson, A., Larsson, E.M., \& Hallstrom, I. (2006a) Impact of extended written information on patient anxiety and image motion artifacts during magnetic resonance imaging. Acta Radiologica, 47(5), 474-80. doi: 10.1080/02841850600690355.

Tornqvist, E., Mansson, A., Larsson, E.M., \& Hallstrom, I. (2006b) It's like being in another worldpatients' lived experience of magnetic resonance imaging. Journal of Clinical Nursing, 15(8), 954-61. doi: 10.1111/j.1365-2702.2006.01499.x.

Wolpe, J., \& Lang, P.J. (1964) A Fear Survey Schedule For Use In Behaviour Therapy. Behaviour Research and Therapy, 2, 27-30.

World Medical Association (2001) World Medical Association Declaration of Helsinki Ethical principles for medical research involving human subjects. Bulletin of the World Health Organization 79(4), 373.

Zigmond, A.S. \& Snaith, R.P. (1983) The hospital anxiety and depression scale. Acta Psychiatrica Scandinavica, 67(6), 361-70. doi: 10.1111/j.1600-0447.1983.tb09716.x. 

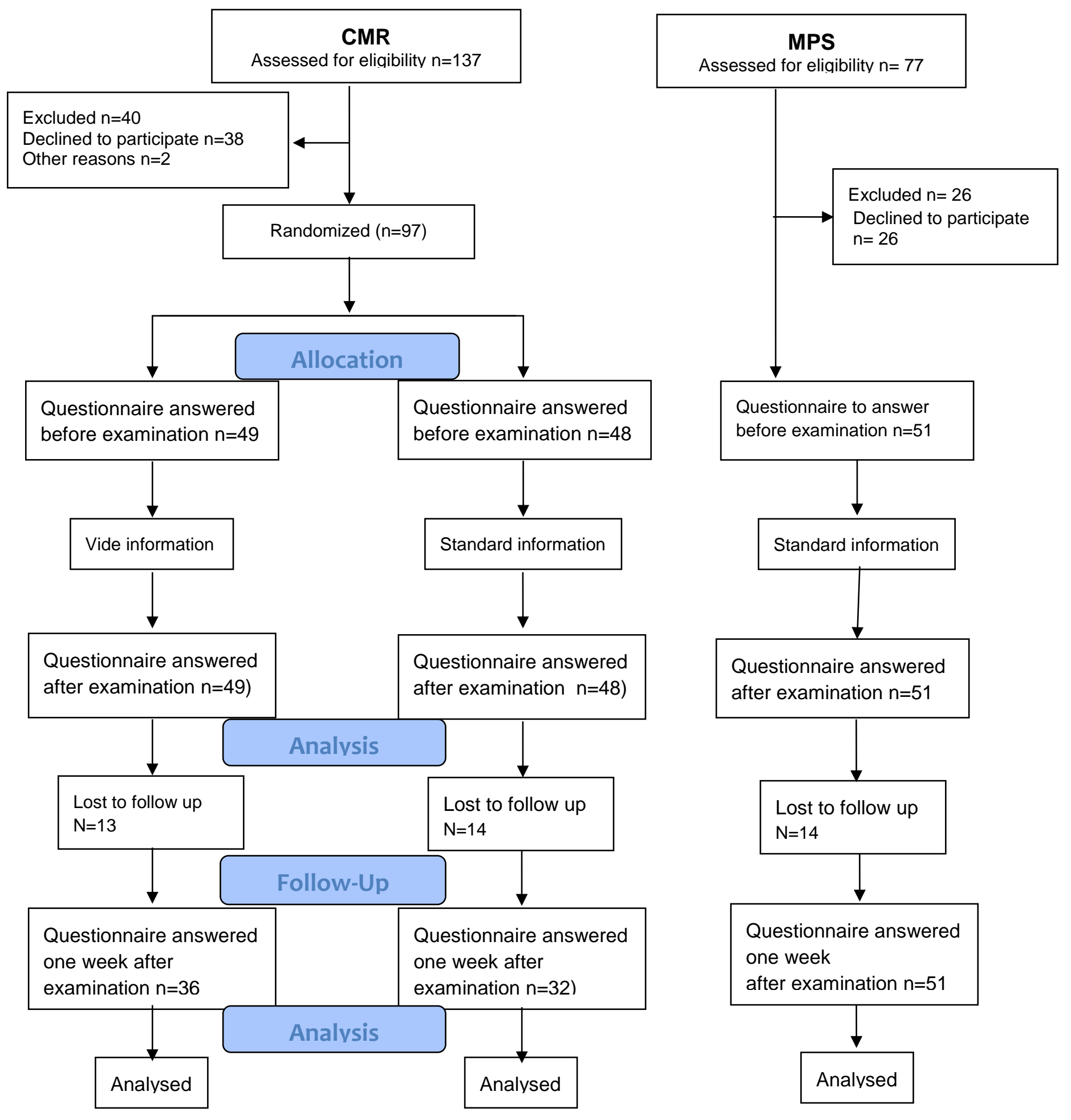

Figure 1. CONSORT Flow Diagram 
Table 1. Overview of study time line and measurements

\begin{tabular}{|c|c|c|c|c|c|c|}
\hline \multirow{2}{*}{$\begin{array}{l}\text { Appointment } \\
\text { letter }\end{array}$} & \multicolumn{5}{|c|}{ On the day of examination at the department of Radiology and Clinical Physiology } & \multirow{2}{*}{$\begin{array}{c}\text { At home } \\
\text { one week } \\
\text { after the } \\
\text { examination }\end{array}$} \\
\hline & Department & $\begin{array}{c}\text { Before } \\
\text { examination }\end{array}$ & Intervention & Examination & $\begin{array}{c}\text { After } \\
\text { examination }\end{array}$ & \\
\hline $\begin{array}{l}\text { The } \\
\text { appointment } \\
\text { letter, } \\
\text { information } \\
\text { about the study } \\
\text { and invitation } \\
\text { to participate }\end{array}$ & $\begin{array}{l}\text { Randomized } \\
\text { CMR-v/CMR-s }\end{array}$ & $\begin{array}{l}\cdot \text { History } \\
\cdot \text { CAQ } \\
\cdot \text { HAD } \\
\cdot \text {-MRI-FSS } \\
\cdot \text {-STAI-S }\end{array}$ & $\begin{array}{l}\text { Extended video } \\
\text { in addition to } \\
\text { standard text- } \\
\text { information } \\
\text { versus only } \\
\text { standard text- } \\
\text { information }\end{array}$ & $\begin{array}{l}\text { CMR } \\
\text { or } \\
\text { MPS }\end{array}$ & $\begin{array}{l}\text {-MRI-AQ } \\
\text {-STAI-S } \\
\text {-Checklist } \\
\text { information } \\
\text {-Checklist staff } \\
\text {-Single items } \\
\text { worry/ } \\
\text { experience } \\
\text { (patient and } \\
\text { staff) }\end{array}$ & $\begin{array}{l}\text {-MRI-AQ } \\
\text {-HAD } \\
\text {-CAQ } \\
\text {-MRI-FSS }\end{array}$ \\
\hline
\end{tabular}

$\mathrm{CMR}=$ Cardiovascular magnetic resonance imaging

$\mathrm{CMR}-\mathrm{v}=\mathrm{CMR}$ with video information, in addition to standard text-information $\mathrm{CMR}-\mathrm{s}=\mathrm{CMR}$ with standard text-information. MPS = myocardial perfusion scintigraphy with standard information

$\mathrm{HAD}=$ Hospital Anxiety and Depression scale, $C A Q=$ Cardiac Anxiety Questionnaire,

STAI-S = Spielberger State Anxiety Index -State,

MRI-FSS = Magnetic Resonance Imaging-Fear Survey Schedule,

MRI-AQ = Magnetic Resonance Imaging- Anxiety Questionnaire,

Checklist information $=$ the participants ranked information on a 10-point scale,

Checklist personnel $=$ the staff informed about the sedative if given and ranked how they perceived patient experience and worry throughout the examination on a ten-point scale. Single items worry/experience=patients rated their worry and experience on a ten-point scale. 
Table 2.

Baseline participant characteristics

\begin{tabular}{|c|c|c|c|c|c|c|}
\hline & & $\begin{array}{c}\text { CMR-v } \\
n=49\end{array}$ & $\begin{array}{c}\text { CMR-s } \\
n=48\end{array}$ & $\begin{array}{l}\text { P-Value } \\
\text { CMR-v } \\
\text { /CMR-s }\end{array}$ & $\begin{array}{l}\text { MPS } \\
N=51\end{array}$ & $\begin{array}{l}\text { P-value } \\
\text { CMR-s } \\
\text { /MPS }\end{array}$ \\
\hline \multicolumn{2}{|l|}{ Female/male ${ }^{\text {a) }}$} & $14 / 35$ & $26 / 22$ & $0.009^{c)}$ & $14 / 37$ & $0.008^{\mathrm{c})}$ \\
\hline \multirow[t]{3}{*}{ Age $^{\text {b) }}$} & All & $49.3 \pm 15.3$ & $49.4 \pm 14.4$ & $0.987^{d)}$ & $64.5 \pm 8.9$ & $<0.001^{d)}$ \\
\hline & Female & $46.8 \pm 12.7$ & $43.8 \pm 13.5$ & $0.498^{\mathrm{d})}$ & $58.8 \pm 9.8$ & $0.001^{d)}$ \\
\hline & Male & $50.30 \pm 16.2$ & $56.0 \pm 12.6$ & $0.170^{\mathrm{d})}$ & $66.6 \pm 7.6$ & $<0.001^{\mathrm{d})}$ \\
\hline \multicolumn{7}{|c|}{ Do you take antihypertensive agents? } \\
\hline Hypertension $^{\text {a) }}$ & Yes & 25 & 20 & $0.418^{c)}$ & 37 & $0.002^{c)}$ \\
\hline \multicolumn{7}{|c|}{ Have you undergone a percutaneous coronary intervention? } \\
\hline $\mathrm{PCl}^{\text {a) }}$ & Yes & 4 & 0 & $0.117^{\mathrm{c})}$ & 18 & $<0.001^{c)}$ \\
\hline \multicolumn{7}{|c|}{ Have you undergone coronary artery bypass graft surgery? } \\
\hline $\mathrm{CABG}^{\mathrm{a})}$ & Yes & 0 & 2 & $0.243^{c)}$ & 8 & $0.093^{c)}$ \\
\hline \multicolumn{7}{|c|}{ Do you medicate, or have you medicated for psychological unhealth? } \\
\hline \multirow{5}{*}{$\begin{array}{l}\text { Medication }{ }^{\text {a) }} \\
\text { If yes when }^{\text {a) }}\end{array}$} & Yes & 8 & 13 & $0.256^{c)}$ & 5 & $0.037^{c)}$ \\
\hline & Ongoing & 4 & 10 & & 0 & \\
\hline & $1-5$ yr ago & 2 & 0 & & 2 & \\
\hline & $6-10 \mathrm{yr}$ ago & 2 & 1 & & 1 & \\
\hline & $11-15$ yr ago & 2 & 3 & & 2 & \\
\hline \multicolumn{7}{|c|}{ Are you, or have you been treated with psychodynamic treatment? } \\
\hline \multirow{5}{*}{$\begin{array}{l}\text { Conversational } \\
\text { therapy } \\
\text { If yes when }^{a)}\end{array}$} & Yes & 8 & 13 & $0.226^{c)}$ & 3 & $0.006^{c)}$ \\
\hline & Just now & 3 & 3 & & 1 & \\
\hline & $1-5$ yr ago & 2 & 5 & & 2 & \\
\hline & $6-10$ yr ago & 3 & 2 & & 0 & \\
\hline & $11-15$ yr ago & 1 & 3 & & 0 & \\
\hline
\end{tabular}

$\left.{ }^{a}\right)=$ number, ${ }^{b)}=$ mean $\pm S D,{ }^{c}{ }^{c}=$ Fisher exact test two-tailed, ${ }^{d)}=$ students t-test

$\mathrm{PCl}=$ percutaneous coronary intervention $\mathrm{CABG}=$ coronary artery bypass graft surgery

$\mathrm{CMR}=$ Cardiovascular magnetic resonance imaging. $\mathrm{CMR}-\mathrm{v}=\mathrm{CMR}$ with video information, in addition to standard textinformation. $\mathrm{CMR}-\mathrm{s}=\mathrm{CMR}$ with standard text-information. MPS= myocardial perfusion scintigraphy with standard information

N.B. Some of the participants are represented in several of the time intervals in the groups with psychological unhealth 


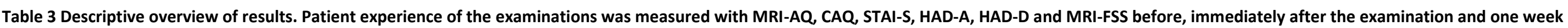

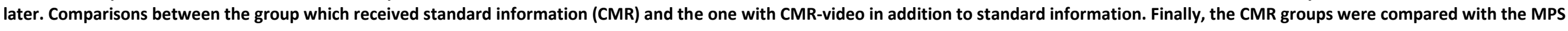
group.

\begin{tabular}{|c|c|c|c|c|c|c|c|c|c|c|c|c|c|c|c|}
\hline \multirow{3}{*}{$\begin{array}{l}\text { Instru- } \\
\text { ments }\end{array}$} & \multicolumn{5}{|c|}{ Before examination } & \multicolumn{5}{|c|}{ Immediately after the examination } & \multicolumn{5}{|c|}{ One week after the examination } \\
\hline & $\begin{array}{c}\text { CMR-S } \\
n=48\end{array}$ & $\begin{array}{c}\text { CMR-V } \\
n=49\end{array}$ & $\begin{array}{c}\mathrm{P}^{*} \\
\text { CMR-s/ } \\
\text { CMR-v }\end{array}$ & $\begin{array}{l}\text { MPS } \\
n=51\end{array}$ & \begin{tabular}{l}
\multicolumn{1}{c}{$\mathrm{P}^{*}$} \\
CMR-S \\
/MPS
\end{tabular} & $\begin{array}{c}\text { CMR-S } \\
n=48\end{array}$ & $\begin{array}{c}\text { CMR-V } \\
n=49\end{array}$ & $\begin{array}{c}P^{*} \\
\text { CMR-s/ } \\
\text { CMR-v }\end{array}$ & $\begin{array}{l}\text { MPS } \\
n=51\end{array}$ & $\begin{array}{c}\mathrm{P}^{*} \\
\text { CMR-s/ } \\
\text { MPS }\end{array}$ & $\begin{array}{c}\text { CMR-S } \\
n=31\end{array}$ & $\begin{array}{c}\text { CMR-V } \\
n=36\end{array}$ & $\begin{array}{c}\mathrm{P}^{*} \\
\text { CMR-s/ } \\
\text { CMR-v }\end{array}$ & $\begin{array}{l}\text { MPS } \\
n=38\end{array}$ & $\begin{array}{c}\mathrm{P}^{*} \\
\text { CMR-s } / \\
\text { MPS }\end{array}$ \\
\hline & \multicolumn{2}{|c|}{$\operatorname{Med}^{\mathrm{a})}\left(\mathrm{IQR}^{\mathrm{b})}\right)$} & & $\operatorname{Med}^{\mathrm{al}}\left(\mathrm{IQR}^{\mathrm{b})}\right)$ & & \multicolumn{2}{|c|}{$\operatorname{Med}^{\mathrm{a})}\left(I Q R^{\mathrm{b})}\right)$} & & $\operatorname{Med}^{a)}\left(I Q R^{b)}\right)$ & & \multicolumn{2}{|c|}{$\operatorname{Med}^{(a)}\left(I Q R^{b)}\right)$} & & $\operatorname{Med}^{a)}\left(\left(Q R^{b)}\right)\right.$ & \\
\hline $\begin{array}{c}\text { MRI-AQ } \\
\text { total }\end{array}$ & & & & & & $22(17-32)$ & $22(18-26)$ & 0.412 & $18(15-21)$ & $<0.001$ & $22(17-31)$ & $22(18.5-27.5)$ & 0.806 & $18(17-20)$ & 0.012 \\
\hline $\begin{array}{l}\text { MRI-AQ } \\
\text { anxiety }\end{array}$ & & & & & & $17(13-26)$ & $17(15-21)$ & 0.792 & $13(12-15)$ & $<0.001$ & $16(13-24)$ & $16(14.5-21)$ & 0.990 & $13(12-15)$ & 0.005 \\
\hline $\begin{array}{l}\text { MRI-AQ } \\
\text { relaxation }\end{array}$ & & & & & & $6(3.5-8.5)$ & $5(3-6)$ & 0.039 & $3(3-6)$ & 0.029 & $5.5(3-7)$ & $5.5(4-6)$ & 0.690 & $5(3-6)$ & 0.232 \\
\hline CAQ total & $22(16.5-34)$ & $19(15-29)$ & 0.112 & $22(12-31.5)$ & 0.328 & & & & & & $22(16-28)$ & $21(16.5-32)$ & 0.930 & $25(15-33)$ & 0.897 \\
\hline $\begin{array}{l}\text { CAQ } \\
\text { Fear }\end{array}$ & $12.5(7-15)$ & $11(8-14)$ & 0.523 & $11(7-15)$ & 0.540 & & & & & & $10(6-16)$ & $12(8.5-15)$ & 0.407 & $10(7-17)$ & 0.869 \\
\hline $\begin{array}{c}\text { CAQ } \\
\text { avoidence }\end{array}$ & $5(2-19)$ & $3(1-9)$ & 0.072 & $7(2-10)$ & 0.717 & & & & & & $7(2-10)$ & $6(1-11)$ & 0.930 & $7(3-11)$ & 0.662 \\
\hline $\begin{array}{c}\text { CAQ } \\
\text { attention }\end{array}$ & $6(4-9)$ & $5(3-7.5)$ & 0.250 & $4.5(2-7)$ & 0.032 & & & & & & $5(3-8)$ & $5(2-7)$ & 0.715 & $4(2-8)$ & 0.535 \\
\hline STAI-S & $35(30-41)$ & $35(28-43)$ & 0.882 & $31(25-40)$ & 0.108 & $30(24-38)$ & $28(22.5-36)$ & 0.201 & $28.5(23-35)$ & 0.214 & & & & & \\
\hline $\begin{array}{c}\text { HAD } \\
\text { anxiety }\end{array}$ & $6.5(3-8.5)$ & $6(2-9)$ & 0.403 & $4(1-7)$ & 0.010 & & & & & & $4(1-8)$ & $3.5(2-5.5)$ & 0.396 & $3(1-6)$ & 0.237 \\
\hline $\begin{array}{c}\text { HAD } \\
\text { depression }\end{array}$ & $2(1-5.5)$ & $2(1-4)$ & 0.691 & $3(1-5)$ & 0.436 & & & & & & $1(1-6)$ & $2(0.5-5)$ & 0.576 & $2(1-6)$ & 0.460 \\
\hline MRI-FSS & $13(9.5-18)$ & $12(10-14.5)$ & 0.286 & $10(9-14)$ & 0.020 & & & & & & $11(9-20)$ & $12(10-14.5)$ & 0.801 & $11.5(10-14)$ & 0.465 \\
\hline $\begin{array}{l}\text { Patient } \\
\text { worry }\end{array}$ & & & & & & $2(1-3)$ & $2(1-3)$ & 0.742 & $1(1-2)$ & 0.008 & $2(1-4)$ & $2(2-3)$ & 0.302 & $1(1-2)$ & 0.103 \\
\hline \begin{tabular}{|c|} 
Patient \\
experience
\end{tabular} & & & & & & $2(1-3)$ & $2(1-3)$ & 0.905 & $1(1-2)$ & 0.094 & $2(1-5)$ & $2(2-3.5)$ & 0.768 & $2(1-3)$ & 0.341 \\
\hline
\end{tabular}

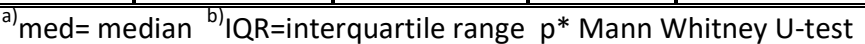

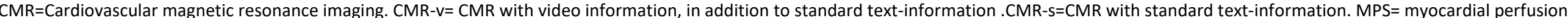

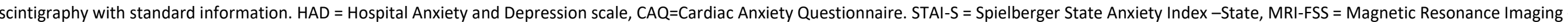

Fear Survey Schedule. MRI-AQ = Magnetic Resonance Imaging- Anxiety Questionnaire. Patient worry and experience single items/10-point scale 
Table 4. Comparison between MRI-AQ total scale and the two factors regarding patient experience of the examinations. Not adjusted and adjusted for age between CMR-s $(m=49.3$ years) and MPS $\left(m=64.5\right.$ years). Not adjusted and adjusted for gender between CMR-s $\left(26 / 22^{c}\right)$ and CMR-v $\left(14 / 35^{c}\right)$.

\begin{tabular}{lcccc}
\hline & $\begin{array}{c}\text { CMR-s/MPS } \\
\mathrm{n}=48 / 51\end{array}$ & $\begin{array}{c}\text { CMR-s/MPS } \\
\mathrm{n}=48 / 51 \\
\text { Adjusted for age }\end{array}$ & $\begin{array}{c}\text { CMR-s/CMR-v } \\
\mathrm{n}=48 / 49\end{array}$ & $\begin{array}{c}\text { CMR-s/CMR-v } \\
\mathrm{n}=48 / 49 \\
\text { Adjusted for gender }\end{array}$ \\
\hline MRI-AQ total & $\begin{array}{c}\mathrm{p} \text {-value } \\
\text { MRI-AQ anxiety }\end{array}$ & $<-$ value $^{\mathrm{b})}$ & $\mathrm{p}$-value & $\mathrm{p}$-value \\
MRI-AQ relaxation & $<0.001$ & $<0.001$ & 0.158 & 0.153 \\
\hline \hline
\end{tabular}

${ }^{\text {a) }}$ t-test, ${ }^{\text {b) }}$ Tukey test, ${ }^{\mathrm{c}}$ female/male

$C M R=C a r d i o v a s c u l a r$ magnetic resonance imaging. $C M R-v=C M R$ with video information, in addition to standard textinformation .CMR-s=CMR with standard text-information. MPS= myocardial perfusion scintigraphy with standard information

\section{Table 5}

The correlation between MRI-AQ scales and measurements of anxiety and depression

\begin{tabular}{llll}
\hline & $\begin{array}{l}\text { MRI-AQ total } \\
\text { scale }\end{array}$ & $\begin{array}{l}\text { MRI-AQ } \\
\text { Anxiety }\end{array}$ & $\begin{array}{l}\text { MRI-AQ } \\
\text { Relaxation }\end{array}$ \\
\hline CAQ total & $0.303^{* * *}$ & $0.296^{* * *}$ & $0.256^{* *}$ \\
CAQ fear & $0.351^{* * *}$ & $0.338^{* * *}$ & $0.276^{* * *}$ \\
CAQ avoidence & 0.052 & 0.040 & 0.070 \\
CAQ attention & $0.256^{*}$ & $0.255^{* *}$ & $0.207^{* *}$ \\
HAD-A & $0.469^{* * *}$ & $0.459^{* * *}$ & $0.359^{* * *}$ \\
HAD-D & 0.150 & 0.130 & $0.173^{*}$ \\
STAI-S & $0.423^{* * *}$ & $0.507^{* * *}$ & $0.359^{* * *}$ \\
MRI-FSS & $0.472^{* * *}$ & $0.396^{* * *}$ & $0.359^{* *}$ \\
Patient experience & $0.487^{* * *}$ & $0.456^{* * *}$ & $0.483^{* * *}$ \\
Patient worry & $0.666^{* * *}$ & $0.684^{* * *}$ & $0.500^{* * *}$ \\
\hline \hline
\end{tabular}

Spearman correlation ${ }^{*} \mathrm{p}<0.05 .{ }^{* *} \mathrm{p}<0.01{ }^{* * *} \mathrm{p}<0.001$

$\mathrm{HAD}=$ Hospital Anxiety and Depression scale, $C A Q=$ Cardiac Anxiety Questionnaire STAI-S = Spielberger State Anxiety Index State, MRI-FSS = Magnetic Resonance Imaging -Fear Survey Schedule, MRI-AQ = Magnetic Resonance Imaging- Anxiety Questionnaire, Patient worry and experience single items/10-point scale 
Table 6

Comparison of MRI-AQ scores between women and men in the two CMRgroups ( $n=96)$.

\begin{tabular}{llll}
\hline & Female $n=40$ & Male $n=56$ & $p$-value ${ }^{\text {b) }}$ \\
\hline MRI-AQ total $^{\text {a) }}$ & $22(18-29)$ & $20(16-23)$ & 0.028 \\
MRI-AQ anxiety $^{\text {a) }}$ & $16.5(13-23)$ & $15(12.5-17)$ & 0.015 \\
MRI-AQ relaxation $^{\text {a) }}$ & $6(3-7)$ & $4(3-6)$ & 0.251 \\
\hline \hline
\end{tabular}

${ }^{\text {a) }}$ Median (interquartile range) ${ }^{\text {b) }}$ Mann-Whitney U-test

$\mathrm{CMR}=$ Cardiovascular magnetic resonance imaging. $C M R-\mathrm{V}=\mathrm{CMR}$ with video information, in addition to standard text-information .CMR-s=CMR with standard text-information. MPS= myocardial perfusion scintigraphy with standard information 